\title{
Sulindac Sulfide
}

National Cancer Institute

\section{Source}

National Cancer Institute. Sulindac Sulfide. NCI Thesaurus. Code C29854.

The active metabolite of sulindac, a sulfinylindene derivative with anti-inflammatory, analgesic and antipyretic properties. Sulindac is a nonsteroidal anti-inflammatory drug (NSAID) which inhibits cyclooxyg enase (COX-1 and-2)-mediated conversion of arachidonic acid to pro-inflammatory prostaglandins. This agent may possess chemopreventive activity against colorectal tumors through a mechanism that involves the induction of apoptosis. The sulfide metabolite is excreted in the bile and reabsorbed from the intestine, thereby helping to maintain constant blood levels and reduce gastrointestinal side effects. ( $\mathrm{NCl04)}$ 